\title{
Professional Association and Pathways to Leadership in Our Profession
}

Mandy Sha*

Keywords: inclusion., diversity, aapor, professional association, leadership

DOI: $10.29115 /$ SP-2018-0039

\section{Survey Practice}

Vol. 12, Issue 1, 2019

The 2019 Interview with the Expert Series starts with a conversation between Courtney Kennedy and Mandy Sha on the topic of pathways to leadership in our profession. Courtney is the chief methodologist at a leading fact tank and chairs the 2019 AAPOR conference. Mandy has 20 years of experience in commercial and noncommercial sectors as well as a university survey shop, and will chair the 2020 AAPOR conference. Drawing upon their own successes and challenges, they provided pragmatic suggestions to early and mid-career professionals who would like to transition into leaders and influencers. Specifically, they talked about leveraging professional association membership in the American Association for Public Opinion Research (AAPOR).

Leadership is the ability to influence, through action, role, or passion. Pathways to leadership in our profession typically include making a research impact, providing significant professional service, and improving the research enterprise and standards. Early- and mid-career professionals can empower themselves to transition into leaders and influencers by leveraging their professional association membership. Support for diversity opens up these pathways to more professionals, and inclusive practices such as discussions about the pathways benefit all professionals who would like to transition into leaders and influencers. This article contributes to that objective with a conversation between Courtney Kennedy and Mandy Sha on the topic of pathways to leadership in our profession. Drawing upon their own successes and challenges, Courtney and Mandy talked about how early- and mid-career professionals can empower themselves by leveraging their professional association membership in the American Association for Public Opinion Research (AAPOR).

Mandy: Courtney, you are one of the most respected survey scientists in our field. I first heard you address the topic of leadership as part of a panel at the 2013 AAPOR conference, and I enjoyed it very much. Could you talk about how you entered the field?

Courtney: Sure, in September 2000, I was a freshman undergraduate in Ann 
Arbor interviewing for various research assistant positions. The job that caught my interest was working for a communications and political science professor, Mike Traugott, studying the performance of polls in that year's presidential election. He hired me, mentored me in the research process, and introduced me to the field of survey methodology. The following year I worked for Mike and Bob Groves on a study evaluating public reactions to the September 11 th attacks. One day Bob summoned me to his office and informed me that I really should get a degree in statistics if I wanted a career in surveys. I took his advice. Both Mike and Bob are remarkable mentors devoted to training the next generation. To say I was fortunate to have them as a gateway into the field would be an understatement.

Mandy: Was there a time when you had to stretch yourself to get where you are professionally?

Courtney: Yes, actually when I was interviewing for that first RA job, I had to really believe in myself. Mike asked if I had experience with Excel. In high school, we never used Excel, so I had only a vague notion that Excel was that green square thingy on a computer. In the moment I knew that if I said "No" I would almost certainly disqualify myself from the job. I quickly thought to myself, when I walk out of this interview I'll bead straight to the bookstore, buy Excel for Dummies, and stay up as late as necessary teaching myself bow to use it. "Yes" I said to Mike. When the interview was over, I did exactly that. I felt reasonably sure I knew what I was doing by about midnight. Over the course of the project, I managed the data first in Excel, later in SPSS, and Mike got the study published in the Public Opinion Quarterly (POQ). Today, there are many accessible and affordable learning resources to enhance your skills, such as the Webinars and in-person short courses offered by AAPOR and by the regional chapters.

Mandy: There are also plenty of self-paced courses people can find online, such as Coursera. Back in 2000, I used a manual like you did! As a MA student, I completed a practicum offered by the university's survey lab and worked there as one of the research assistants. I didn't stand out from other RAs until I borrowed a manual and taught myself to program CATI surveys and automate case management. I had to stretch myself? The full-time job they created for me after I graduated led to my first AAPOR paper and gave me the confidence to pursue a career in public opinion research. There is a path to leadership for those who do not have a PhD or the "right" degree! Students who are interested in learning more about career paths and graduate studies in the fields of public opinion and survey research should check out AAPOR's SurveyFest.

Courtney: Our field is notable in how applied it is, while also having strong scientific and academic influences. Thinking about past AAPOR presidents, some built their own companies. Some did groundbreaking research. Some contributed by generously volunteering their time and expertise. They don't necessarily have a long list of publications. One thing that has made AAPOR 
strong over the years is that we've had leaders and influencers from industry, academe, and government.

Mandy: My first work supervisor pointed out to me that AAPOR provided a robust environment to network with people from industry, academe and government. As a non-native English speaker who didn't have connections out of school, 'networking' just sounded daunting! At one conference, I volunteered to help the attendees put up their posters. The experience made me realize that volunteering was a direct and natural way to interact with other members and leaders. Serving also made me feel good! After volunteering on several AAPOR committees, I identified the annual conference as an area that I have a passion for. I started as a volunteer at conference events, then an assistant to the event coordinator, later I coordinated events, and eventually I led the subcommittee that oversaw all of those events. Last year, I was elected associate conference chair. I've collaborated with many AAPOR members over the years!

Courtney: That's a good example to show that volunteering at the annual conference and standing committees are opportunities you can cultivate. You don't necessarily need to know someone. When you apply or renew your AAPOR membership, you have the opportunity to check a box expressing interest in a particular committee or you can fill out the online volunteer form. To be even more proactive, people go to AAPOR's committee webpage and contact the chair of the committee for which they have a passion, but more importantly contact the associate chair. The reason of the contact is to say "I'd really like to serve on this committee, here's why, and here is my relevant experience." Often the chair has already filled the vacant spots for the year. But the associate chair, who is the incoming chair next year, has not yet made those decisions. That kind of email gets you on their radar. I strongly suggest committee service as a way to develop expertise and leadership skills. For people just entering the field, there is a lot to be said for starting at the local chapter level where volunteering and leadership opportunities may be more accessible.

Mandy: I love my regional chapter! I've been able to contribute my strategic communications experience that I never get to do at AAPOR because they have professionals for those activities. And I like what you said about being proactive - it puts you in control because you could be clear on what and how you would like to contribute. You create your own narrative. To me, volunteering for many roles or always saying "yes" is not a sustainable approach. I recommend that people identify and pursue roles they have a passion for. Working on what you love while making friends along the way is also more fun! Committee meetings are usually by phone - international members can participate, too! For those interested in learning more, a 2018 AAPOR Webinar provided comprehensive information about volunteering and leadership opportunities on committees, subcommittees, groups, and the regional chapters. This Webinar recording is free! 
Courtney: There are many other professional associations relevant to our profession that rely on volunteers, such as World Association for Public Opinion Research (WAPOR), Insights, Association of Academic Survey Research Organizations (AASRO), European Survey Research Association (ESRA), American Statistical Association (ASA), etc., as well as associations that focus on substantive issues.

Mandy: Let's say an early or mid-career professional has been doing all of this. To become a leader and influencer, they must be seen as one. How do they leverage their AAPOR membership to be seen as leaders and influencers?

Courtney: Right, AAPOR offers many opportunities for members to develop their professional reputation. Making scientific contributions certainly accelerates the process. In addition to $\mathrm{POQ}$, another peer-reviewed Oxford journal published by AAPOR is the Journal of Survey Statistics and Methodology. AAPOR's e-journal Survey Practice focuses on current and practical information. In addition, many of the leaders I've looked up present their work at the annual conference. They also serve as session moderators or simply ask good questions and make helpful suggestions.

Mandy: You can also be recognized for your expertise by contributing to the vibrant discussions on AAPORnet - messages are delivered to all subscribers, including leading professionals in the field! Entering competitions hosted by AAPOR is another way. For example, AAPOR's Got Talent is a competition in which AAPOR members develop original ideas and research design to address a pressing issue in survey research, and then present their ideas to a panel of judges and attendees at the annual conference. Students can also enter the annual Seymour Sudman Student Paper Competition and Student Poster Competition. Winners of these competitions are recognized for their scientific contributions. You can't win if you don't stretch yourself and give it a try!

Courtney: That's right, and for more mid-career professionals, service on one of AAPOR's ad-hoc committees and task forces can raise your visibility. Each year, they produce white paper reports on important issues. These are often highly cited publications, and the process allows you to work with ten to fifteen leaders in the field. If you are fortunate enough that you have a mentor on the task force, it's a natural entrée, perhaps in a research assistant capacity. Similarly, it can be a huge boost professionally if your mentor allows you to coauthor or collaborate on a project that they do outside of AAPOR. Mentors get you over that initial hump toward leadership.

Mandy: After getting over the initial hump, mentors will continue to illuminate your path. When I started my own business, an important client came to me thanks to the recommendation of a mentor I had met at AAPOR. Early in my career, I saw that being hardworking was not "enough" to propel me beyond the early successes. I needed mentors besides work supervisors. AAPOR connected me with many senior researchers and leaders. At first, 
it was hard to develop a relationship with them because few had much in common with me in terms of our background. Through my committee service and conference presentations, people got to know me better and I learned more about my own strengths and weaknesses. I started getting breaks. I even got to know some senior people from my then employer who later mentored me! I am indebted to many mentors from AAPOR who have helped me with scientific and leadership opportunities that at the time I could not have initiated on my own. I wrote an AAPOR newsletter article in which I presented three recommendations for early-career professionals, including tips on developing a successful mentoring relationship. Those recommendations came from interviews with nine advanced career AAPORites!

Courtney: Mentoring and collaboration are crucial for those who have the will but are still building experience. One approach is to partner with a senior researcher to co-present a webinar or a short course. That can be a powerful way to increase scientific stature. Your name is connected to a research topic, which communicates you are an expert on that topic every time the event is being publicized. Presenters' pictures are on multiple emails, on the association website, and social media postings. In most cases, the senior person would be happy to have you do the legwork, such as prepping the slides. This way, they can stay engaged and active themselves and delegate the work that would make them normally turn the opportunity down. Before you approach the senior researcher, you should first establish credibility through prior publications, conference presentations, or professional service. Webinars or short courses require substantial qualifications, and with the senior person as a co-presenter, the proposal has a greater chance of acceptance with AAPOR or the chapter sponsoring the event.

Mandy: Collaboration among like-minded peers can be powerful, too, especially for those who don't already have a mentor, are not well connected, or are still trying to figure out their strengths and weaknesses in relation to reaching their goals. Several years ago, two other AAPOR members and I started an affinity group to connect researchers who share our passion for cross-cultural and multilingual research. Many of our collaborators need more opportunities to publish and to increase visibility. Since 2016, we've collaborated to publish special issues in two journals and our collaborators organized conference sessions. AAPOR took notice and specified in AAPOR Working Group on Long Term Diversity report on what the organization would do to support affinity groups! To join or start an affinity group, submit an application to AAPOR. There you can also read about additional affinity groups like QUALPOR and $\underline{\text { HISP-AAPOR. }}$

Courtney: That's being proactive! If you've got the will, you should have the confidence and place a bet on yourself to do what's necessary for the next step... Be willing to take that next step: apply to graduate school, a job, or intimidating opportunities. Stretch yourself! 
Mandy: That's such an inspiring quote! I'd like to end with what 2018 AAPOR award recipient Lars Lyberg said in his acceptance speech: You are nothing without networks. So to those of you who are young or not so young, you should keep yourself visible. Join groups, offer your services, if possible, get a mentor. Yogi Berra said "if you ain't visible, no one will see you." (But he didn't, I made that up!). Professional associations such as AAPOR can empower the leader and influencer within among early- and mid-career professionals!

\section{Contact Information}

Author: Mandy Sha

Email: mandy@mandysha.com

Website: www.mandysha.com 